\title{
Material Selection of Machine Design using Expert System: A Comparative Study
}

\author{
Prithwiraj Jana
}

\begin{abstract}
This research venture one of the major concerns in the field of expert system. Material selection an important key issue of machine design. Objectives of computerized selection procedure are reduced to personal bias and gives the more accurate optimized result. The concept of entropy; to evaluate the weight factor for each alternative material property or performance index, and the other is TOPSIS and SAW; to rank the candidate materials, for which several requirements are considered simultaneously. Sensitivity analysis is introduced here for better performance of selection.
\end{abstract}

Keywords: Flywheel, Material selection, TOPSIS, SAW, Entropy, Sensitivity analysis

\section{INTRODUCTION}

ver the years, selection of materials plays a crucial role for value addition in production, cost optimization, better product development and improve productivity in machine design. Flywheel is an important machining component. In this paper, optimization theory is applied for right selection of flywheel manufacturing process. Multiple criteria decision making (MCDM) is the process of selecting the best alternative from a set of feasible alternatives considering multiple conflicting criteria. In precise terms criteria are considered to be 'strictly' conflicting if the increase in satisfaction of one result in a decrease in satisfaction of the other.

\subsection{Entropy}

Originally Entropy is a thermodynamic concept, first introduced by Shannon. It has been widely used in the engineering, socioeconomic and other fields. According to the basic principles of information theory, information is a measure of system's ordered degree, and the entropy is a measure of system's disorder degree. Step1Calculate (the ith scheme's jth indicator value's proportion). $\mathrm{pij}=\mathrm{rij} /$ $\sum_{i=1}^{m}=$ rij, rijis the ith scheme's jth indicator valueStep2 Calculate the jth indicator's entropy value becomesej.ej= -k $\sum_{j=1}^{m}$ pijln pij, $\mathrm{k}=1 / \mathrm{ln} \mathrm{m}, \mathrm{m}$ is the number of assessment schemes.Step3 Calculate weight wj (jth indicator's weight). $\mathrm{wj}=(1-\mathrm{ej}) / \sum_{j=1}^{n}(1-\mathrm{ej}), \mathrm{n}$ is the number of indicators, and $0 \leq$ $\mathrm{wj} \leq 1, \sum_{j}^{n} w \mathrm{w}=1$

\footnotetext{
Manuscript received on 31 March 2021 | Revised Manuscript received on 05 April 2021 | Manuscript Accepted on 15 April 2021 |Manuscript published on 30 April 2021.

* Correspondence Author

Prithwiraj Jana*, Bachelor's Degree, Production Engineering, Haldia Institute of Technology, West Bengal, India.

(C) The Authors. Published by Lattice Science Publication (LSP). This is an open access article under the CC-BY-NC-ND license (http://creativecommons.org/licenses/by-nc-nd/4.0/)
}

In entropy method, the smaller the indicator's entropy value ej is, the bigger the variation extent of assessment value of indicators is, the more the amount of information provided, the greater the role of the indicator in the comprehensive evaluation, the higher its weight should be.

1.2 Technique for Order Preference by Similarity to Ideal Solution (TOPSIS)

TOPSIS is an evaluation method that is often used to solve MCDM problems. It has a number of applications in practice, such as comparison of company performances, financial ratio performance within a specific industry and financial investment in advanced manufacturing systems, etc. However, there are also some limits to it. So far, the work on how to improve original TOPSIS method has mainly emphasized on improving the weight to sensitize the $\mathrm{R}$ value. Besides, there has also been improvement on formula of the $\mathrm{R}$ value, such as the 'Miqiezhi' method. Because of the complexity of evaluation problems, a better and simpler method is required to understand the inherent relationship between the $\mathrm{R}$ value and alternative evaluation. In this report, a novel, modified TOPSIS (M-TOPSIS) method is described as a process of calculating the distance between the alternatives and the reference points in the $\mathrm{D}+\mathrm{D}^{-}$-plane and constructing the $\mathrm{R}$ value to evaluate quality of alternative.

\subsection{SIMPLE ADDITIVE WEIGHTING (SAW)}

Step 1 Formation of decision matrix: Criterion outcomes of decision alternatives can be collected in a table called Decision Matrix comprised of a set of columns and rows. The matrix rows represent decision alternatives, with matrix columns representing criteria. A value found at the intersection of row and column in the matrix represents a criterion outcome - a measured or predicted performance of a decision alternative on a criterion. The decision matrix is a central structure of the MCDA/MCDM since it contains the data for comparison of decision alternatives.

\subsection{Sensitivity Analysis}

In actual situation decision-making is rather dynamic process not static. It varies in the continuous changing environment. In reality the value of decision making attitude depends upon decision maker's personal choice. Under such circumstances decision making attitude behaves as a variable that may yield different results. Keeping it in mind, the proposed model for the selection of material has been enhanced by sensitivity analysis to provide a readymade solution of the current problem under variable decision making attitude. The governing equation of the material measure (MM) is given by $M M_{i}=\alpha\left(O F M_{i}-S F M_{i}\right)+S F M_{i}$

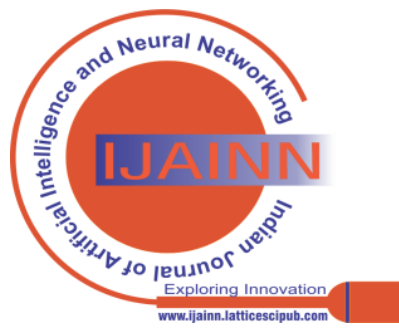


where, $\mathrm{i}=1,2 \ldots \mathrm{m}$.

OFMi= Objective factor measure for the alternative $\mathrm{i}$

$\mathrm{SFMi}=$ Subjective factor measure for the alternative $\mathrm{i}$

$\alpha=$ Objective factor decision weight/Coefficient of attitude

\section{PROCEDURE OF CASE STUDY}

An organization has got 10 different materials with different specifications for flywheel. The decision maker considered 5 selection criteria.

The materials are as follows

The selection criteria are as follows:

Table-01

\begin{tabular}{|c|c|}
\hline C1 & Density (g/cm3) \\
\hline C2 & Hardness (BHN) \\
\hline C3 & Young's modulus (GPa) \\
\hline C4 & Bulk Modulus (GPa) \\
\hline C5 & Poisson's ratio \\
\hline C6 & Cost (INR) Per kg \\
\hline
\end{tabular}

Out of 6 criteria, 4 criteria viz. C2:Hardness (Bhn), C3: Young's modulus (GPa),C4: Bulk Modulus (GPa),C5: Poisson's ratio are beneficial criteria because their higher values are desirable and remaining viz. C1: Density $(\mathrm{g} / \mathrm{cm} 3)$
C7: Cost (INR) Per kg are non-beneficial criteria because their lower values are desirable.

The objective of the decision maker is to assess the performance of the materials. Counseling the above 6 criteria

Table-2

\begin{tabular}{|c|c|c|c|c|c|}
\hline MATERIAL & $\begin{array}{c}\text { olimit } \\
(\mathrm{MPa})\end{array}$ & $\begin{array}{l}\text { KIC } \\
(\mathrm{MPa} / \mathrm{m} 1 / 2)\end{array}$ & $\begin{array}{l}\text { Density } \\
103 \mathrm{~kg} / \mathrm{m} 3\end{array}$ & $\begin{array}{l}\text { Price/mass } \\
\text { (US\$/Ton) }\end{array}$ & Fragmentability \\
\hline $300 \mathrm{M}$ & 800 & 68.9 & 8 & 4200 & 3 \\
\hline 2024-T3 & 140 & 38 & 2.82 & 2100 & 3 \\
\hline 7050-T73651 & 220 & 35.4 & 2.82 & 2100 & 3 \\
\hline Ti-6Al-4V & 515 & 123 & 4.73 & 10500 & 3 \\
\hline E glass]epoxy FRP & 140 & 20 & 2 & 2735 & 9 \\
\hline Carbon]epoxy FRP & 700 & 35 & 1.59 & 35470 & 7 \\
\hline Kevlar 29-epoxy FRP & 340 & 40 & 1.4 & 11000 & 7 \\
\hline Kevlar 49-epoxy FRP & 900 & 50 & 1.46 & 25000 & 7 \\
\hline Boron]epoxy FRP & 1000 & 46 & 2 & 315000 & 5 \\
\hline
\end{tabular}

to ultimately select the best material. The decision maker applied TOPSIS and MOORA methods for their simplicity, adaptability, applicability and is of applications. The decision matrix for the materials with respect to the criteria shown below:
Computational result by MATLAB:

2.1 Entropy Method:

III. RESULT

Table-3

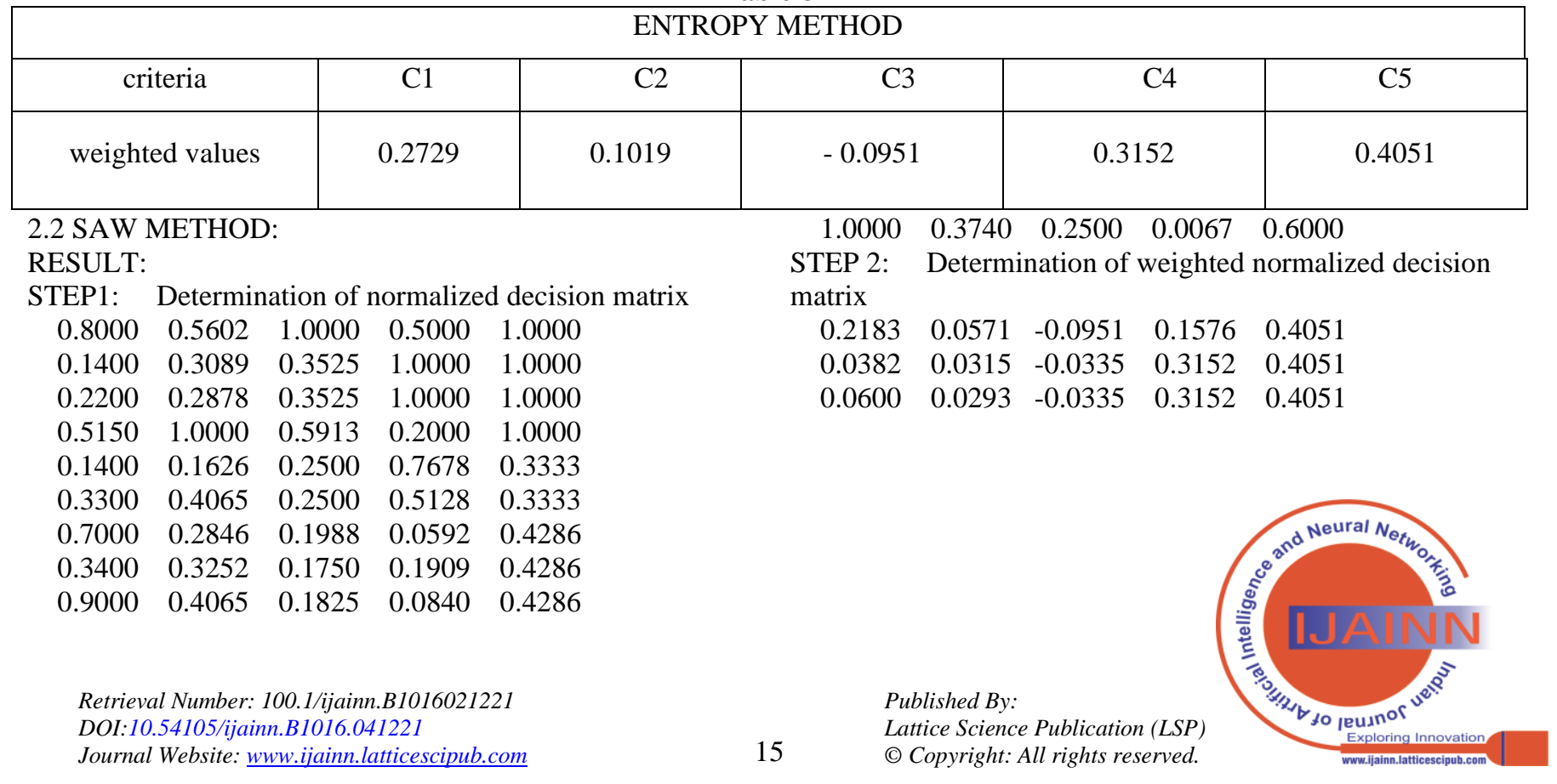




$\begin{array}{ccccc}0.1406 & 0.1019 & -0.0563 & 0.0630 & 0.4051 \\ 0.0382 & 0.0166 & -0.0238 & 0.2420 & 0.1350 \\ 0.0901 & 0.0414 & -0.0238 & 0.1617 & 0.1350 \\ 0.1910 & 0.0290 & -0.0189 & 0.0187 & 0.1736 \\ 0.0928 & 0.0331 & -0.0166 & 0.0602 & 0.1736 \\ 0.2456 & 0.0414 & -0.0174 & 0.0265 & 0.17360 .2729 \\ 0.0381 & -0.0238 & 0.0021 & 0.2431 & \end{array}$

STEP 3: Computation of composite score s......by sum of all weighted normalized rows

The values of (s) are:

$\begin{array}{llllll}0.7430 & 0.7565 & 0.7762 & 0.6543 & 0.4081 & 0.4044 \\ 0.3934 & 0.3431 & 0.4698 & 0.5324 & & \end{array}$

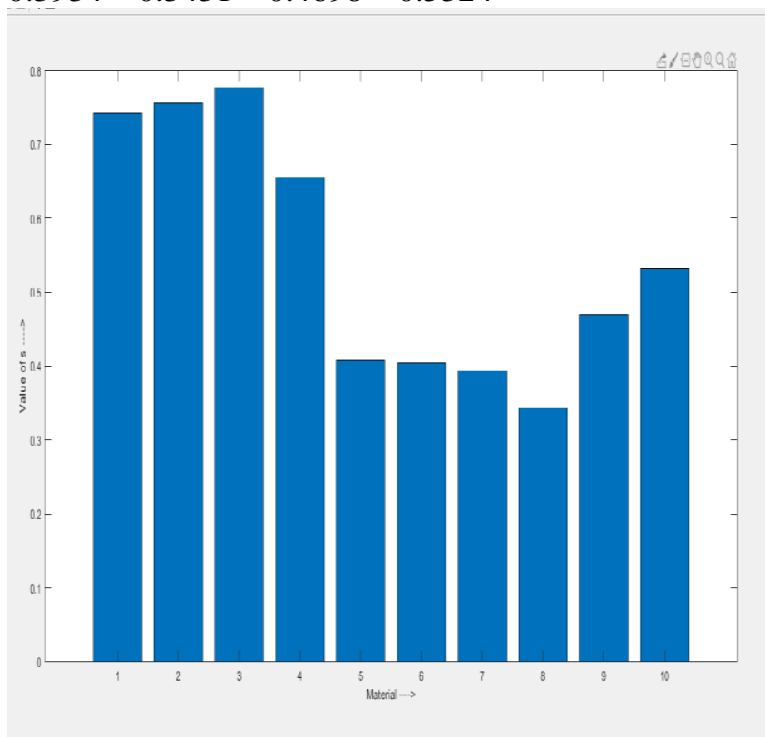

Fig:01

2.3 To determine the sensitivity analysis graph by SAW: The value of closeness co-efficient in SAW method when alpha $=0$ when alpha $=1$
0.56270 .1803
$0.7203 \quad 0.0361$
$0.7203 \quad 0.0558$
$0.4681 \quad 0.1862$
0.37710 .0310
$0.2967 \quad 0.1077$
$0.1923 \quad 0.2011$
0.23380 .1093
$0.2001 \quad 0.2697$
$0.2452 \quad 0.2872$

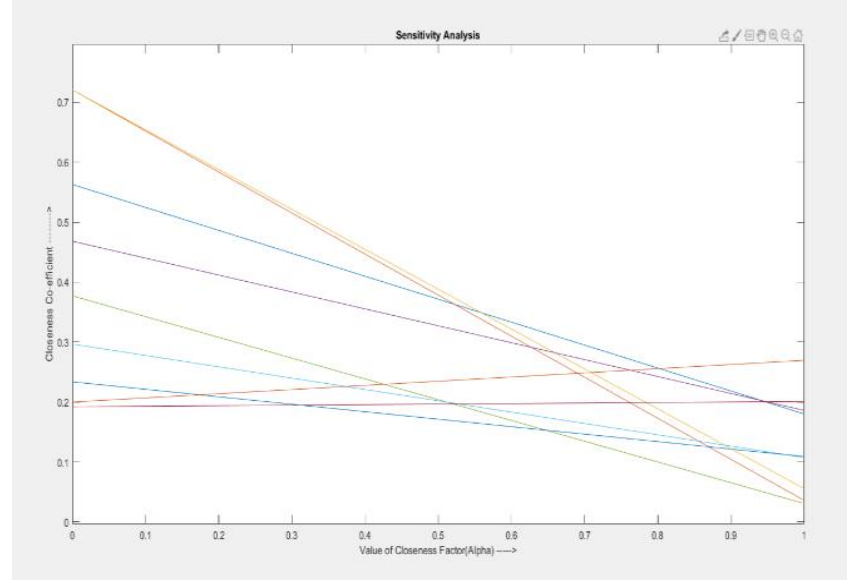

Fig:02
The weighted values are:

$\begin{array}{lllll}0.2729 & 0.1019 & -0.0951 & 0.3152 & 0.4051\end{array}$

1.2 The weighted values got from entropy method

STEP1: Determination of normalized decision

matrix

$\begin{array}{lllll}0.8000 & 0.5602 & 1.0000 & 0.5000 & 1.0000 \\ 0.1400 & 0.3089 & 0.3525 & 1.0000 & 1.0000 \\ 0.2200 & 0.2878 & 0.3525 & 1.0000 & 1.0000 \\ 0.5150 & 1.0000 & 0.5913 & 0.2000 & 1.0000 \\ 0.1400 & 0.1626 & 0.2500 & 0.7678 & 0.3333 \\ 0.3300 & 0.4065 & 0.2500 & 0.5128 & 0.3333 \\ 0.7000 & 0.2846 & 0.1988 & 0.0592 & 0.4286 \\ 0.3400 & 0.3252 & 0.1750 & 0.1909 & 0.4286 \\ 0.9000 & 0.4065 & 0.1825 & 0.0840 & 0.4286 \\ 1.0000 & 0.3740 & 0.2500 & 0.0067 & 0.6000\end{array}$

STEP 2:

Determination of positive ideal solution: taking the maximum values of each column from the normalized decision matrix

$$
\begin{array}{lllll}
1 & 1 & 1 & 1 & 1
\end{array}
$$

Determination of negetive ideal solution: taking the minimum values of each column from the normalized decision matrix

$$
\begin{array}{lllll}
0.1400 & 0.1626 & 0.1750 & 0.0067 & 0.3333
\end{array}
$$

STEP 3:

Calculation of the seperation measure from the positive ideal solution(di_Plus)

0.3308,,0.4589,,0.4217,,0.5001,,0.6456,,0.5998,,0.6 $534,, 0.6627,, 0.6098,0.6019$

Calculation of the seperation measure from the negetive ideal solution(di_Minus)

0.5718,, 0. 7002,, 0.7010,, 0.5340,, 0.4267,, 0.3101,, 0.3026,, 0.1673,, 0.4114,, 0.4844

Calculation of $\mathrm{R}$ i

$$
\begin{array}{lllll}
0.6335 & 0.6041 & 0.6244 & 0.5164 & 0.3979
\end{array}
$$$$
\begin{array}{lllll}
0.3408 & 0.3166 & 0.2016 & 0.4029 & 0.4459
\end{array}
$$

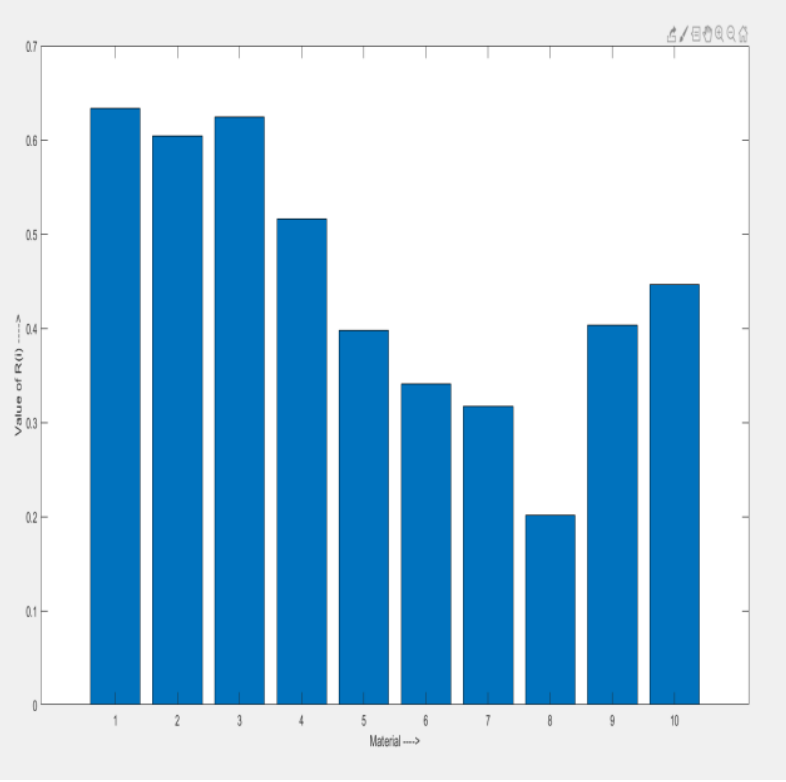

Fig:03

2.5 Comparative analysis of ranking of flywheel materials using MCDM methods

2.4 TOPSIS method

In the TOPSIS method

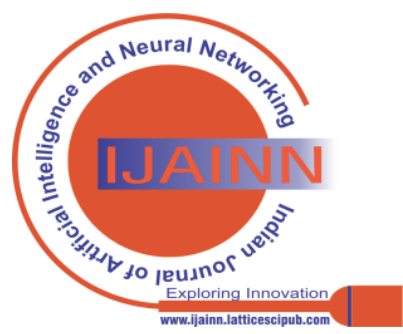


Material Selection of Machine Design using Expert System: A Comparative Study

Table-4

\begin{tabular}{|c|c|c|}
\hline MATERIAL & MOORA & TOPSIS \\
& (RANK) & 1 \\
\hline M1 & 2 & 3 \\
\hline M2 & 3 & 5 \\
\hline M3 & 5 & 2 \\
\hline M4 & 1 & 4 \\
\hline
\end{tabular}

\section{CONCLUSION}

The use of TOPSIS and MOORA methods are inspected to be quite capable and computationally easy to appraise and select the proper material from a given set of alternatives. These methods use the measures of the considered criteria with their relative importance in order to arrive at the final ranking of the alternative flywheel Materials. We have used the MATLAB, by this software we can also make rank of any system for any number of alternatives and criteria within a fraction of second with accuracy. Thus, these popular MCDM methods can be successfully employed for solving any type of decision-making problems having any number of criteria and alternatives in the manufacturing domain. In this study, cost is an important key issue in material selection. For a product development, cost optimization is necessary.

\section{REFERENCES}

1. Wei Z. An extended TOPSIS method for multiple attribute decision making based on intuitionistic uncertain linguistic variables. Engineering Letters. 2014; 22(3):1-9.

2. Takahashi K, Kitade S, Morita H. Development of high speed composite flywheel rotors for energy storage systems. Advanced Composite Materials. 2002; 11(1):40-9. [CrossRef]

3. Jain M, Ramachandran M. Buy/Make decision making framework for pump product development with multi criteria decision making. International Journal of Applied Engineering Research. 2015; 10(11):10486-9

4. Sandstrom R. An approach to systematic materials selection.Mater Des 1985;6:328]337. [CrossRef]

5. Ashby MF. Overview No.80: on the engineering properties of materials. Acta Metall Mater 1989;37(5)::1273-1293. [CrossRef]

6. Waterman NA, Ashby MF. Elsevier material selector. Elsevier Applied Science, 1992

7. Fleck NA, Kang KJ, Ashby MF. The cyclic properties ofengineering materials. Acta Metall Mater 1994; 42(2).:365-381. [CrossRef]

8. Prithwiraj Jana, Pranab Kumar Dan (2017) OPTIMIZATION TREATMENT OF MATERIAL SELECTION IN MACHINE DESIGN - CONSIDERING TECHNICAL, ECONOMIC AND SUPPLY ASPECT. ISJ Theoretical \& Applied Science, 03 (47): 128-138. [CrossRef]

9. D-H. Jee, K-J. Kang. A method for optimal material selection aided with decision making theory, Materials \& Design, Vol.21, No.3, 199-206, 2000. [CrossRef]

10. Dipali Rai , Goutam Kumar Jha , Prasenjit Chatterjee, Shankar Chakraborty, "Material Selection in Manufacturing Environment Using Compromise Ranking and Regret Theory-based Compromise Ranking Methods: A Comparative Study," Universal Journal of Materials Science, Vol. 1, No. 2, pp. 69 - 77, 2013. DOI: 10.13189/ujms.2013.010210[CrossRef]

11. Pulkit Purohit* and M. Ramachandran, "Selection of Flywheel Material using Multicriteria Decision Making Fuzzy Topsis", Indian Journal of Science and Technology, Vol 8(33), DOI: 10.17485/ijst/2015/v8i33/80028, December, 2015[CrossRef]

\section{AUTHORS PROFILE}

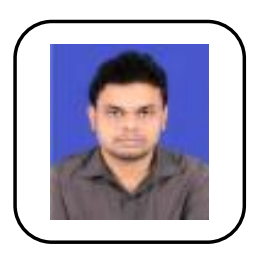

P. Jana born in India 1990. Obtained his Bachelor's degree in Production Engineering, from Haldia Institute of Technology, during 2008-2012. \& Master's degree from School of Engineering \& Technology (Gov.) under West Bengal University of Technology in the Industrial Engineering \& Management during 2012-2014.He is having about 02 years industrial experience in Inspection department, I.O.C.L(Haldia Refinery) and having 08 International journals / Conference papers. He also obtained his professional qualification on A.S.N.T. (The American Society For Nondestructive Testing) Level-II (UT, DPT, MPT, RT).He is also an author of engineering books. Former assistant professor of Haldia Institute of Technology

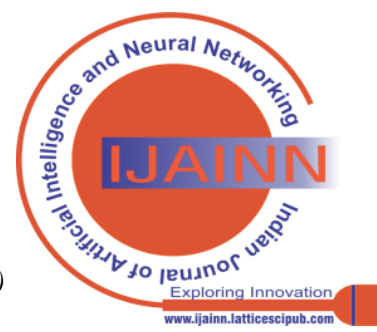

